\title{
Opioid Treatment Patterns Following Prescription of Immediate-Release Hydrocodone
}

\author{
Rami Ben-Joseph, PhD; Jill A. Bell, PhD; Diana Brixner, PhD; Anuraag Kansal, PhD; \\ Clark Paramore, MSPH; Abhishek Chitnis, MPharm, PhD; Pamela Holly, JD; \\ and Douglas S. Burgoyne, PharmD
}

\begin{abstract}
BACKGROUND: Immediate-release (IR) hydrocodone is the most widely prescribed opioid in the United States; however, little is known about the utilization patterns and duration of opioid use among patients prescribed IR hydrocodone. A better understanding of the use of IR hydrocodone would result in more appropriate prescribing patterns of extended-release opioids.

OBJECTIVE: To assess downstream length of opioid therapy and utilization patterns of extended-release/long-acting (ER/LA) opioids among patients on IR hydrocodone to provide a better understanding of how IR and ER/LA opioids are used to manage pain.

METHODS: Retrospective analysis using health care claims from the Truven MarketScan Commercial, Medicare Supplemental, and Medicaid databases was performed. Patients prescribed IR hydrocodone during the 6-month baseline period (July 2011-December 2011) and with continuous enrollment for a 12-month follow-up period (2012) post-index date (January 1, 2012) were selected. Downstream length of therapy, defined as number of days supplied with opioids, and downstream use of ER/LA opioids during followup were examined by average pills per month ( $\leq 60 \mathrm{vs.}>60$ pills per month) and days supply ( $<60$ vs. $\geq 60$ days supply) of IR hydrocodone during baseline to mimic intermittent and consistent IR users.
\end{abstract}

RESULTS: At baseline, 1,743,933 commercial, 277,096 Medicare, and 157,922 Medicaid IR hydrocodone patients were identified. During followup, $1.7 \%, 2.9 \%$, and $2.8 \%$ of patients initiated (i.e., converted to or newly started) ER/LA opioids for commercial, Medicare, and Medicaid groups, respectively. Approximately $90 \%$ of patients were prescribed IR hydrocodone for less than 2 months in the following year, while $10 \%$ were high utilizers, averaging nearly 8 months of prescribed opioid use during followup. Downstream initiation of ER/LA opioids was significantly higher among commercial patients prescribed IR hydrocodone for $>60$ pills per month than with $\leq 60$ pills per month $(7.8 \%$ vs. $1.2 \%$, respectively, $P<0.05)$ at baseline. For commercial patients initiating ER/LA opioids, length of ER/LA therapy during follow-up was significantly longer among patients with baseline IR hydrocodone $>60$ pills per month than with $\leq 60$ pills per month. All results were consistent when examined by levels of days supply.

CONCLUSIONS: A majority of the population prescribed IR hydrocodone was not prescribed opioid therapy beyond 2 months on average in the 1-year follow-up period. Only a small subset of patients with increased pills per month or days supply of IR hydrocodone in the baseline period continued to be high utilizers in the following year, averaging nearly 8 months of prescribed opioid use. A limited proportion of patients prescribed IR hydrocodone converted to ER/LA opioids. This knowledge can assist policymakers and physicians, providing an opportunity to identify small subsets of patients to improve ER/LA opioid prescribing.

J Manag Care Spec Pharm. 2016;22(4):358-66

Copyright $\odot 2016$, Academy of Managed Care Pharmacy. All rights reserved.

\section{What is already known about this subject}

Opioids are widely prescribed, particularly immediate-release (IR) hydrocodone, but there exists substantial variation in the opioid use duration across patients.

Overall, higher use of IR hydrocodone during an initial period has been found to predict longer duration of continued use after that period.

\section{What this study adds}

This study is the first to describe longitudinal, real-world utilization patterns for patients taking IR hydrocodone; including downstream utilization of long-acting opioids.

Knowledge of utilization patterns and duration of opioid use can inform more targeted use of extended-release/long-acting (ER/LA) opioids.

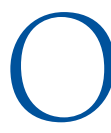
pioid medication is widely used in the management of chronic pain with nearly 10 million U.S adults estimated to have received long-term opioid therapy in 2013 alone. ${ }^{1}$ Several observational studies noted an increase in the rate of opioid prescribing between the year 2000 and 2009..$^{2-5}$ Between 2009 and 2013, the rate of opioid prescriptions declined by $9.2 \%$, yet the number of prescriptions filled per patient and the days supply of medication increased by $8.4 \%{ }^{1}$

Studies have shown noticeable variation in duration of opioid therapy. At the national level, nearly $15 \%$ of the U.S. population fills at least 1 opioid prescription in any given year, but only $20 \%$ of these individuals continue to use this pain medication beyond 30 days. ${ }^{1}$ For individuals in the United States who continue to take opioid medication for more than 30 days in their first year of use, about half persist in using opioids for 3 years or longer, and in this more chronic group of patients, more than half are still prescribed only short-acting opioids. ${ }^{1}$ In 2008, results from the CONsortium to Study Opioid Risks and Trends (CONSORT) study in managed care settings found that patients classified as having long-term opioid therapy were likely to continue frequent opioid use in future years. ${ }^{6}$ Paulozzi et al. (2014) examined administrative claims for patients with employer-based insurance and determined that individuals with more days supply in their initial period of opioid use had longer overall durations of opioid use. ${ }^{7}$ 


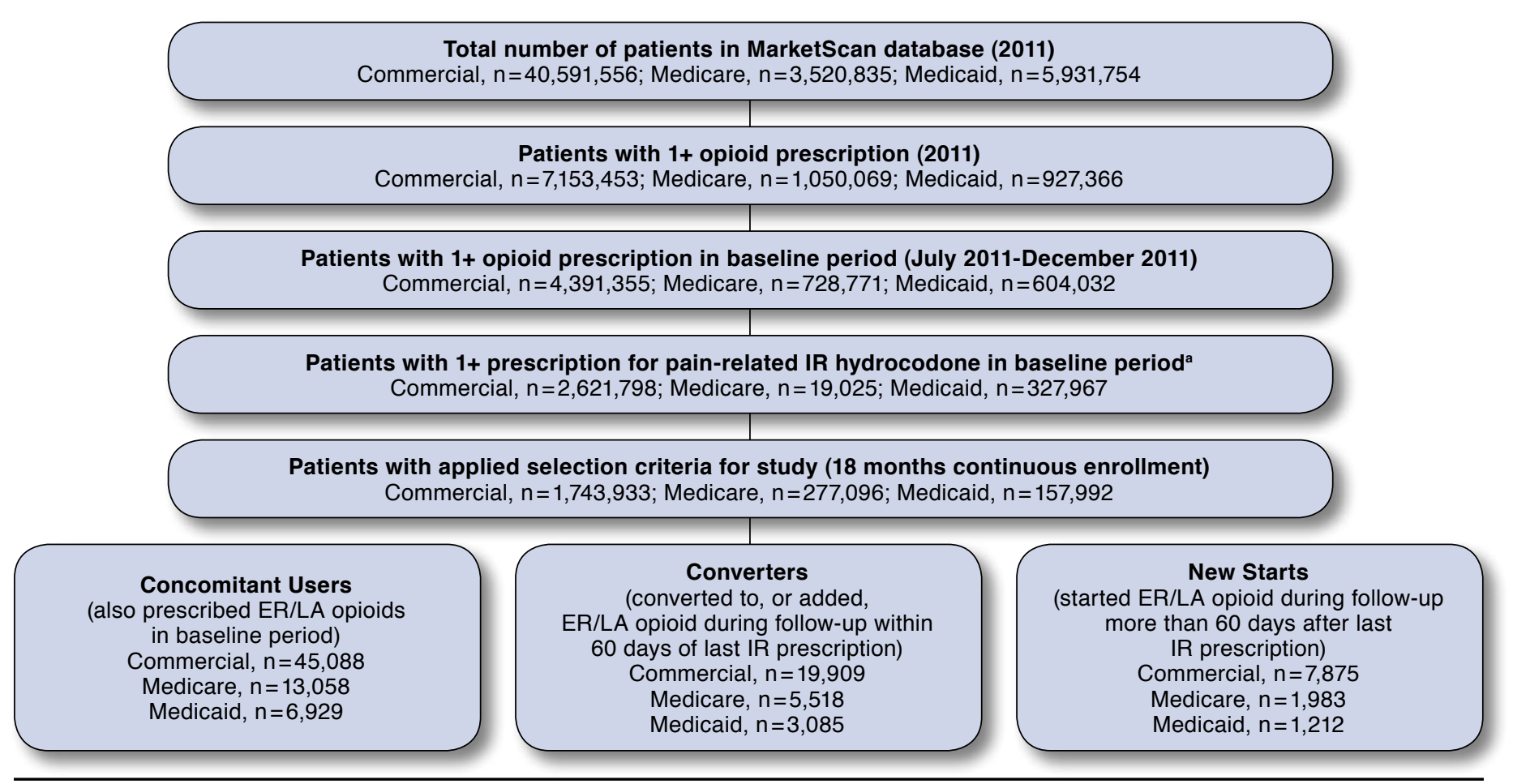

a Prescriptions for IR hydrocodone that were not pain related (e.g., antitussive or sympathomimetic) were excluded. $E R / L A=$ extended-release/long-acting; $I R=$ immediate release.

Immediate-release (IR) hydrocodone is the most widely prescribed opioid in the United States for management of moderate to moderately severe pain; however, little is known about the pattern and duration of opioid use among IR hydrocodone patients specifically. ${ }^{8}$ Understanding this population's use of extended-release/long-acting (ER/LA) opioids is necessary in view of the reported shift to greater prescribing of potent, longacting opioids in recent years. ${ }^{3,5,9}$ The purpose of this study is to assess downstream length of opioid therapy and utilization patterns of opioids among IR hydrocodone patients to better inform appropriate transitions to ER/LA opioids and to provide a better understanding of how IR and ER/LA opioids are used to manage pain.

\section{Methods}

\section{Data Source}

This study used administrative claims data from the 20112012 Truven MarketScan Commercial Claims and Encounters Research Database, Medicare Supplemental Database, and Medicaid Multistate Database..$^{10}$ The MarketScan data are submitted by employers, managed care organizations, hospitals, and Medicare and Medicaid programs. The MarketScan data provide a nationally representative sample of Americans with employer-provided health insurance. The databases capture the full continuum of care in all settings, including, but not limited to, physician office visits; hospital stays; and retail, mail order, and specialty pharmacies. Medical services and prescriptions completely paid out of pocket or paid by other supplemental insurances were not captured in the database. Moreover, they allow tracking of patients over multiple years and also across health plans. In addition, the MarketScan databases contain detailed outpatient prescription drug information. Since these databases are primarily used for research purposes, they are Health Insurance Portability and Accountability Act compliant and thus exempt from institutional review board approvals. ${ }^{10}$

\section{Sample Selection}

The study period consisted of a 6-month baseline period (July 1 , 2011-December 31, 2011) and a 12-month follow-up period (January 1, 2012-December 31, 2012). January 1, 2012, was designated as the index date to allow a 1-year follow-up until the end of 2012. Individuals with at least 1 claim for an oral IR hydrocodone prescription for pain during the 6-month baseline period were included in this study. Any IR hydrocodone prescription that was not pain related (e.g., therapeutic class descriptions for antitussive or sympathomimetic) was 
Opioid Treatment Patterns Following Prescription of Immediate-Release Hydrocodone

TABLE 1 Baseline Patient Characteristics, by Payer Type and ER/LA Use Status

\begin{tabular}{|c|c|c|c|c|c|c|}
\hline & \multicolumn{6}{|c|}{ Baseline Patient Characteristics } \\
\hline & All & Concomitan & & Converters & New Starts & $\begin{array}{l}\text { Nonusers of } \\
\text { ER/LA Opioids }\end{array}$ \\
\hline \multicolumn{7}{|c|}{ Commercial $(\mathrm{n}=1,743,933)$} \\
\hline Total (n) & $1,743,933$ & \multicolumn{2}{|c|}{45,088} & 19,909 & 7,875 & $1,671,061$ \\
\hline Age, mean (SD) & $44.3 \quad(13.6)$ & $50.3 \quad(10.0$ & & $49.4 \quad(10.5)$ & $48.3 \quad(11.4)$ & $44.1 \quad(13.7)$ \\
\hline Gender, \% female & 56.2 & \multicolumn{2}{|l|}{57.8} & 58.5 & 57.0 & 56.2 \\
\hline CCI, mean (SD) & $0.7 \quad(1.2)$ & \multicolumn{2}{|c|}{$\begin{array}{ll}1.4 & (1.9) \\
\end{array}$} & $1.3 \quad(1.9)$ & $1.4 \quad(2.1)$ & $0.6 \quad(1.2)$ \\
\hline ER/LAOI (\%) & & Oxycodone & $(26.8)$ & & & \\
\hline ER/LAO2 (\%) & & Fentanyl & $(24.7)$ & & & \\
\hline ER/LAO3 (\%) & & Morphine sulfate & $(19.9)$ & & & \\
\hline Other ER/LAO (\%) & & All other ER/LAO & $(28.6)$ & & & \\
\hline \multicolumn{7}{|c|}{$\begin{array}{l}\text { Medicare }(n=277,096) \\
\end{array}$} \\
\hline Total (n) & 277,096 & \multicolumn{2}{|c|}{13,058} & 5,518 & 1,983 & 256,537 \\
\hline Age, mean (SD) & $75.2 \quad(7.8)$ & $74.4 \quad(9.0$ & & $75.4 \quad(8.3)$ & $75.6 \quad(8.4)$ & $75.2 \quad(7.7)$ \\
\hline Gender, \% female & 56.7 & \multicolumn{2}{|c|}{64.0} & 62.7 & 60.4 & 56.1 \\
\hline CCI, mean (SD) & $1.9 \quad(1.9)$ & \multicolumn{2}{|c|}{$(2.4)$} & $(2.4)$ & $(2.6)$ & (1.9) \\
\hline ER/LAOl (\%) & & Fentanyl & $(43.8)$ & & & \\
\hline ER/LAO2 (\%) & & Oxycodone & $(20.9)$ & & & \\
\hline ER/LAO3 (\%) & & Morphine sulfate & $(16.8)$ & & & \\
\hline Other ER/LAO (\%) & & All other ER/LAO & $(18.5)$ & & & \\
\hline \multicolumn{7}{|c|}{ Medicaid $(\mathrm{n}=157,992)$} \\
\hline Total (n) & 157,992 & \multicolumn{2}{|c|}{6,929} & 3,085 & 1,212 & 146,766 \\
\hline Age, mean (SD) & $37.5 \quad(15.7)$ & $47.6 \quad(11.7$ & & $46.8 \quad(12.0)$ & $44.7 \quad(12.8)$ & $36.8 \quad(15.7)$ \\
\hline Gender, \% female & 28.4 & 65.1 & & 67.9 & 66.0 & 72.0 \\
\hline CCI, mean (SD) & $1.3 \quad(1.8)$ & $2.5 \quad(2.4$ & & $2.4 \quad(2.3)$ & $2.4 \quad(2.5)$ & $1.3 \quad(1.7)$ \\
\hline ER/LAOl (\%) & & Morphine sulfate & $(30.1)$ & & & \\
\hline ER/LAO2 (\%) & & Oxycodone & $(21.8)$ & & & \\
\hline ER/LAO3 (\%) & & Fentanyl & (18.4) & & & \\
\hline Other ER/LAO (\%) & & All other ER/LAO & $(29.7)$ & & & \\
\hline
\end{tabular}

excluded. Drugs considered in this study are listed in the Appendix (available in online article). Patients were required to have continuous insurance enrollment, both medical and pharmacy, for the 6-month baseline period and for the 12-month follow-up period. The sample selection criteria for the study are presented in Figure 1.

\section{Study Measures}

Patients meeting the selection criteria from the combined databases (commercial, Medicare supplemental, and Medicaid) were classified into 4 subgroups based on utilization patterns of opioids: (1) patients who were prescribed IR hydrocodone and ER/LA opioids (listed in the Appendix) during the baseline period (concomitant users); (2) patients who were using only IR hydrocodone at baseline and converted to an ER/LA opioid during the follow-up period within 60 days of their last day of IR hydrocodone use (converters); (3) patients who were using only IR hydrocodone at baseline and started an ER/LA opioid during the follow-up period more than 60 days after their last day of IR hydrocodone use and were newly prescribed ER/LA opioids (new starts); and (4) patients who were using only IR hydrocodone at baseline and did not use an ER/LA opioid at any point during the follow-up period (nonusers of ER/LA opioids). The opioids identified in the study were prescription based and did not include nonmedical use of medications. Baseline demographic characteristics including age and gender were reported for each patient. Clinical status was assessed during the baseline period using the Charlson Comorbidity Index (CCI) by summarizing the overall burden of potential comorbid diseases within the claims data. ${ }^{11}$ The rate of initiation of ER/LA opioids (i.e., combined rate of conversions and new starts) during the follow-up period were assessed by payer type.

Downstream length of therapy was defined as total number of days supplied with opioid during the follow-up period. Overlapping fill days from prescriptions were considered only once to avoid summing of fill days over the overlapping days. Downstream length of therapy was assessed in all 4 subgroups: (1) concomitant users, (2) converters, (3) new starts, and (4) nonusers of ER/LA opioids. Where applicable, downstream 


\section{A. Commercial Patients}

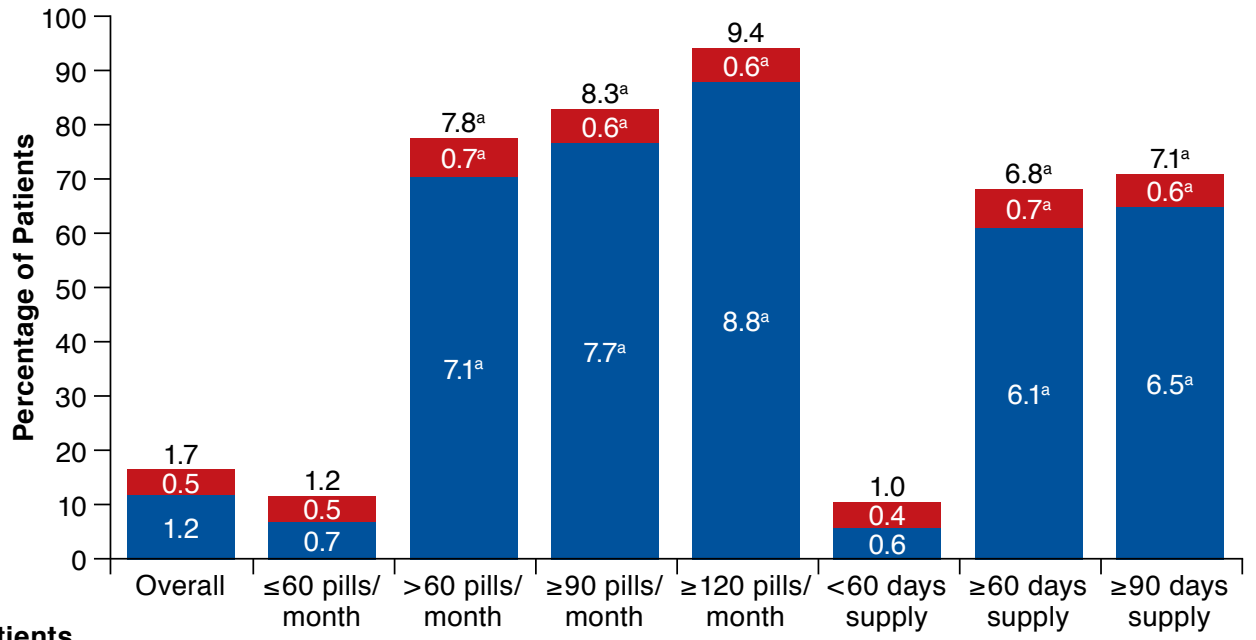

\section{B. Medicare Patients}

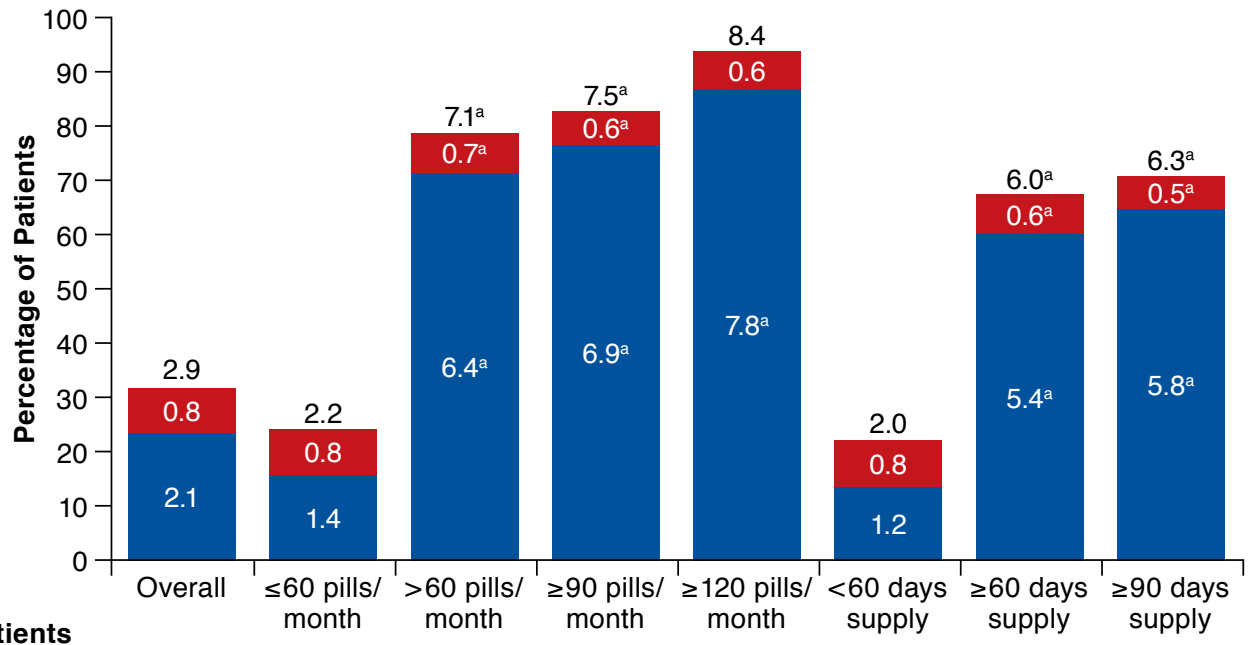

\section{Medicaid Patients}

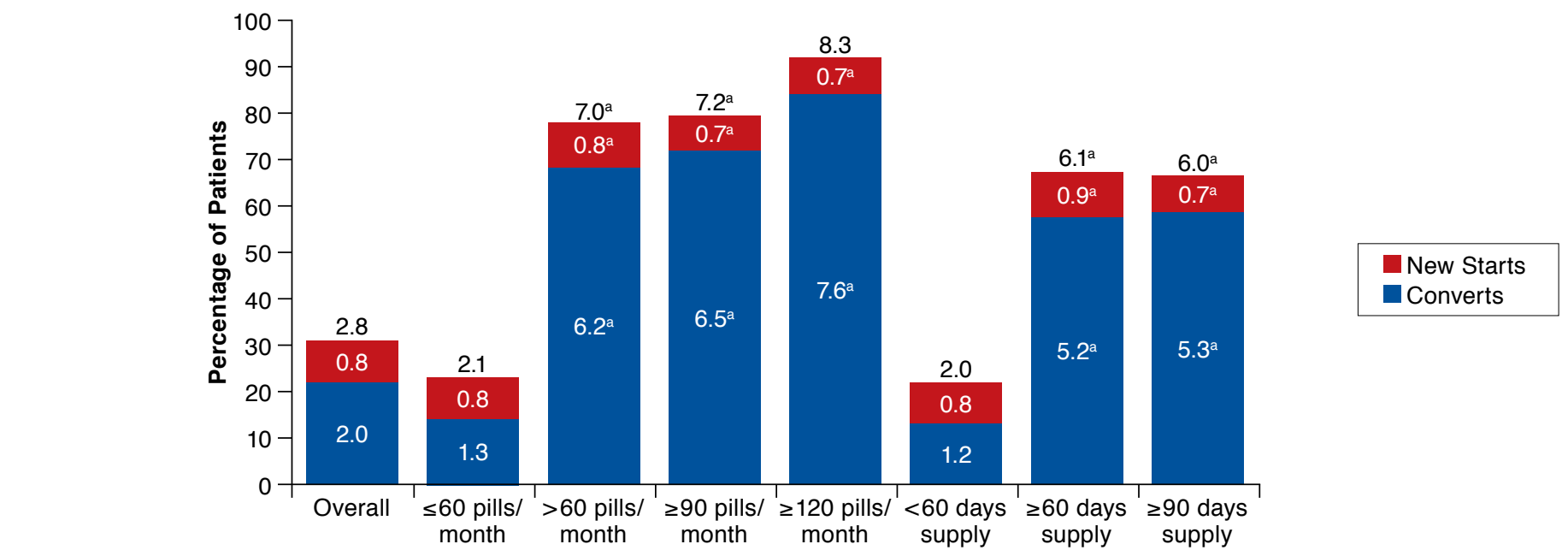

New Starts

Converts

a $P<0.05$ compared with $\leq 60$ pills per month or $<60$ days supply subgroup. 
length of therapy was calculated for both ER/LA opioid use (concomitant users, converters, and new starts) and IR hydrocodone use (nonusers of ER/LA opioids).

\section{Stratified Analysis}

Patients were further stratified by levels of pill count and days supply of IR hydrocodone in the baseline period. Downstream study measures assessed in the follow-up period, including rates of initiation of ER/LA opioids and length of therapy, were further assessed according to these baseline stratifications.

The average number of pills per month (pills per month, sometimes referred to as pill count) was calculated as total number of IR hydrocodone pills prescribed during the baseline period divided by 6 months. The average number of pills per month was categorized into $\leq 60,>60, \geq 90$, and $\geq 120$ pills per month. Days supply was defined as the longest period of consecutive days supplied during the baseline period. A maximum gap of 30 days between the end of 1 prescription and the pick-up of the next was allowed to reflect real-world behavior (e.g., delays in picking up prescriptions and nonadherence). The categories included $<60, \geq 60$, and $\geq 90$ days supply. Initial cut-offs for the $>60$ pills per month and $\geq 60$ days supply subpopulations were defined a priori to identify patients that received more than 2 pills per day on average, or a minimum of 2 full months of therapy (at least 1 monthly refill), respectively.

\section{Statistical Analysis}

Analyses were conducted separately for the commercial, Medicare supplemental, and Medicaid-eligible samples. Mean and standard deviation (SD) were used to describe the continuous variables; frequency and percentages were used to describe categorical variables. Chi-square tests and analysis of variance (ANOVA) were used for categorical and continuous variables, respectively, to test the differences between the study groups. For all the analyses, $P$ value $<0.05$ was considered to be statistically significant. The data were processed and analyzed using SAS version 9.4 (SAS Institute, Cary, NC).

\section{Results}

A total of 1,743,933 commercially insured, 277,096 Medicare, and 157,992 Medicaid patients prescribed IR hydrocodone were identified based on study inclusion criteria (Figure 1). Table 1 provides a summary of baseline characteristics. For concomitant users in the commercial setting, the most common ER/LA opioid during baseline was oxycodone (26.8\% of patients), followed by fentanyl (24.7\%), and morphine (19.9\%). Fentanyl was the most common ER/LA opioid for the Medicare sample (43.8\%) while morphine was most common for the Medicaid sample (30.1\%).

Rates of Initiation of ER/LA Opioids During Follow-up Period The rates of conversion to ER/LA opioids in the follow-up period for patients prescribed only IR hydrocodone at base- line were $1.2 \%(n=19,909)$ for commercially insured patients, 2.1\% ( $n=5,518)$ for Medicare patients, and 2.0\% ( $n=3,085)$ for Medicaid patients. The rates of new starts of ER/LA opioids were $0.5 \%(n=7,875)$ for commercially insured patients, $0.8 \%(n=1,983)$ for Medicare patients, and $0.8 \%(n=1,212)$ for Medicaid patients. Overall, combining these 2 groups (converters and new starts), the rates of initiation of ER/LA opioids during follow-up among patients with only IR hydrocodone use at baseline were $1.7 \%, 2.9 \%$, and $2.8 \%$ in the commercial, Medicare, and Medicaid populations, respectively (Figure 2A-C).

Patients prescribed $>60$ pills per month of IR hydrocodone in baseline period had a higher rate of initiation of an ER/LA opioid in the follow-up period when compared with patients prescribed $\leq 60$ pills per month, regardless of insurance type. Similarly, patients prescribed $\geq 60$ day's supply of IR hydrocodone at baseline were more likely to initiate an ER/LA opioid in the follow-up period than were patients prescribed $<60$ days supply, again regardless of insurance type (Figure 2A-C).

\section{Downstream Length of Therapy During Follow-up Period}

Downstream mean length of therapy with ER/LA opioids during the follow-up period was 183.9 days, 177.9 days, and 193.2 days for concomitant users in the commercial, Medicare, and Medicaid groups, respectively. For converters, length of therapy with ER/LA opioids was 85.4 days, 75.7 days, and 92.8 days, respectively, and for new starts it was 70.6 days, 69.2 days, and 90.3 days, respectively (Figure 3A). Among commercially insured concomitant users, downstream length of ER/LA opioid therapy in the follow-up period was significantly longer among patients with $>60$ pills per month in the baseline period (229.5 days) compared with those with $\leq 60$ pills per month in the baseline period (147.8 days). For initiators, downstream length of ER/LA opioid therapy was also longer for patients prescribed $>60$ pills per month in the baseline period (103.6 days for converters and 82.6 days for new starts) compared with those prescribed $\leq 60$ pills per month in the baseline period (70.2 days for converters and 69.1 days for new starts; Figure 3A). Similar results were found for commercially insured concomitant users when examining downstream length of therapy by baseline days supply (228.2 days of ER/LA opioid therapy for patients with $\geq 60$ days supply as compared with 137.5 days for patients with $<60$ days supply). Length of therapy for converters and new starts was also longer for patients prescribed $\geq 60$ days supply in the baseline period (100.7 days for converters and 87.4 days for new starts) compared with those prescribed $<60$ days supply in the baseline period (68.6 days for converters and 67.5 days for new starts; Figure 3B). The aforementioned trends were similar for the Medicare and Medicaid populations except for new starts in Medicaid, where there were no statistically significant differences in the downstream length of therapy by baseline pills per month and days supply. 


\section{FIGURE 3 Downstream Mean Length of Therapy (in Days) for ER/LA Opioids During Follow-up by Baseline} Pills Per Month and Days Supply

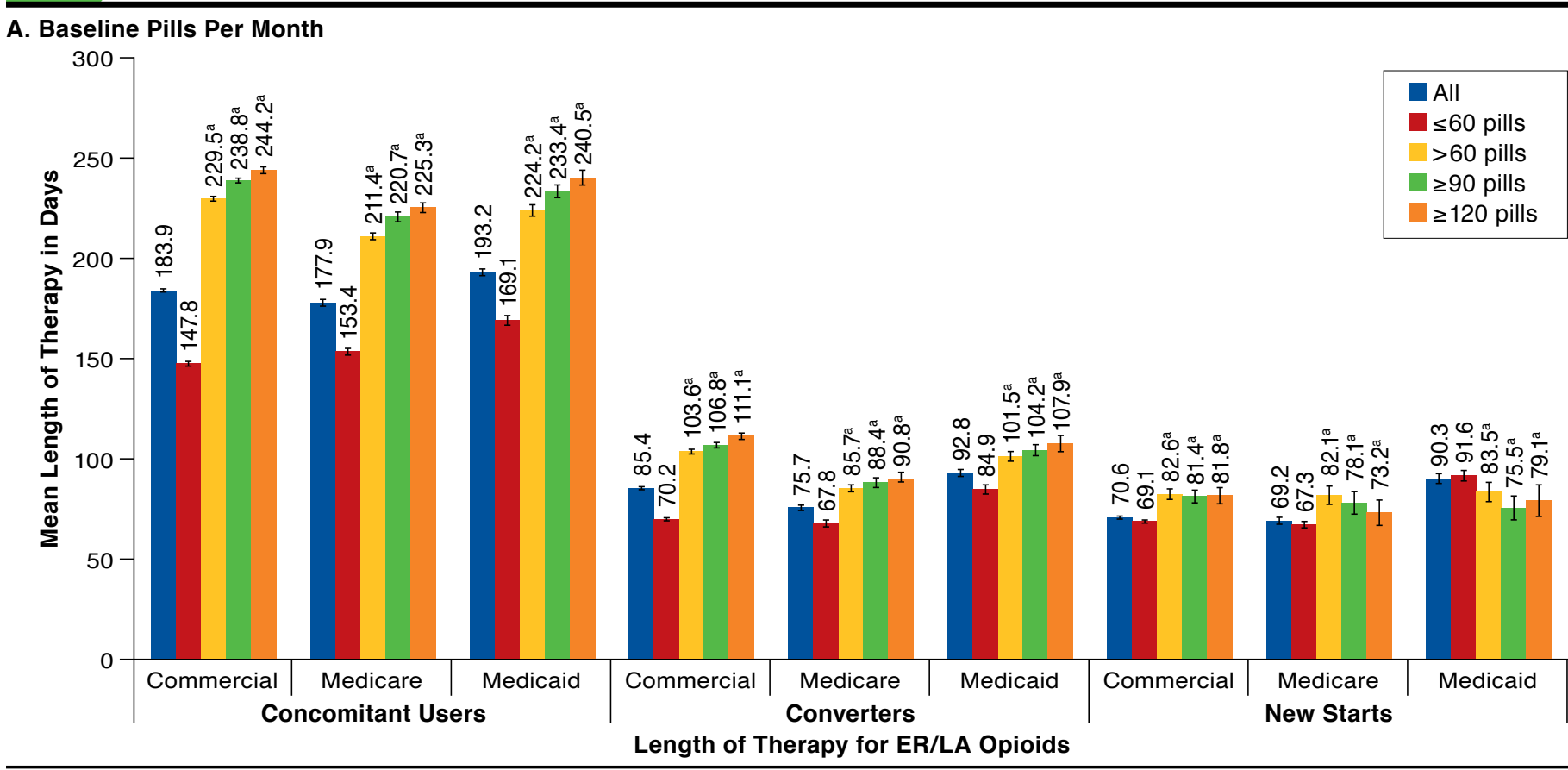

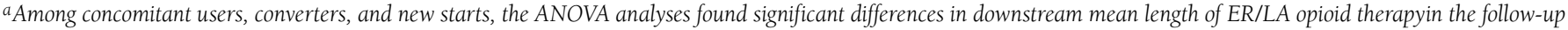

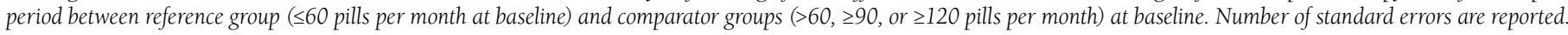
ER/LA = extended-release/long-acting.

\section{B. Baseline Days Supply}

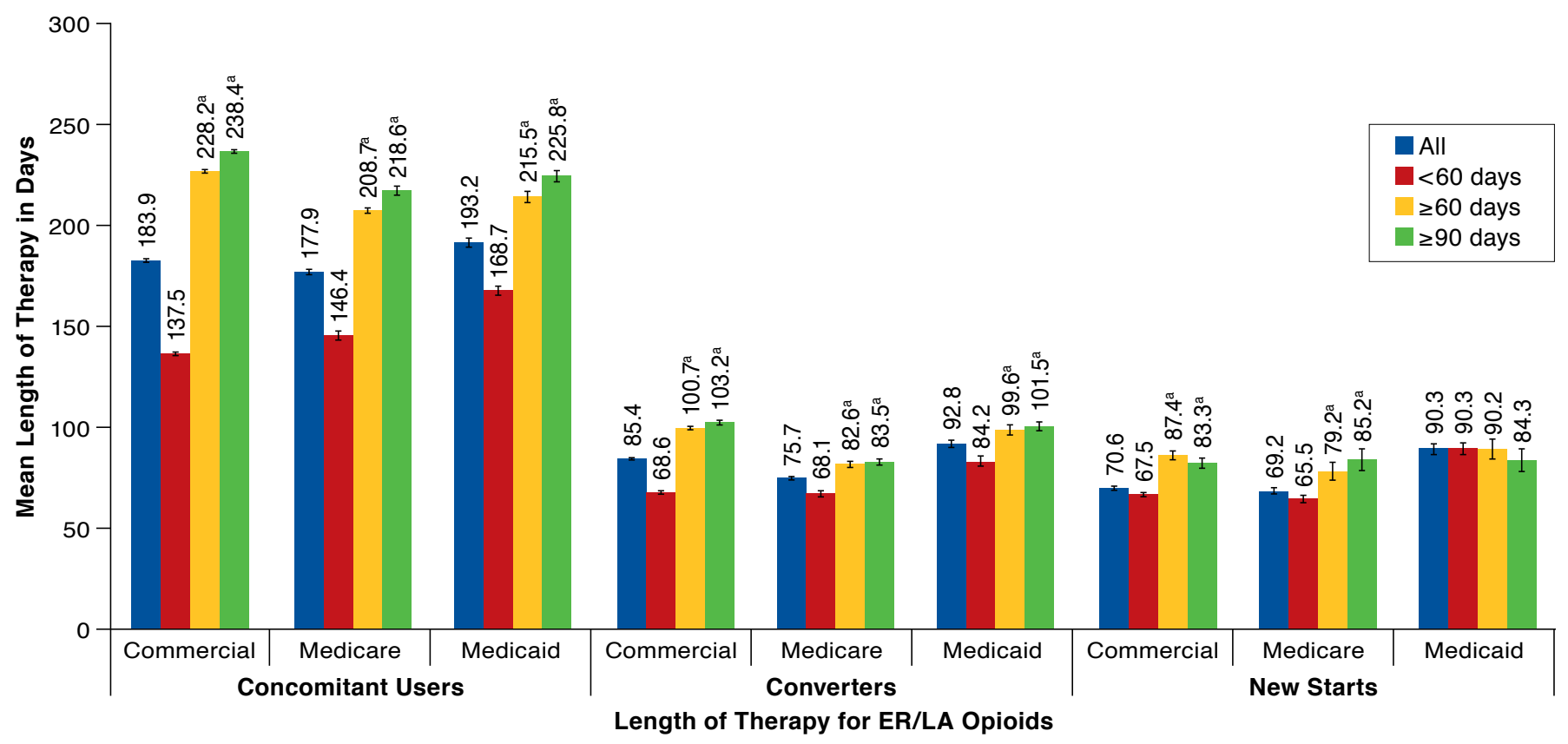

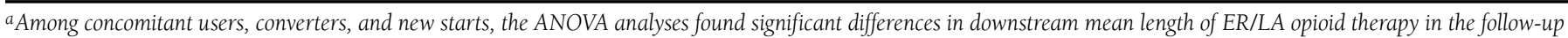
period between reference group (<60 days supply) and other comparison groups ( $\geq 60$ or $\geq 90$ days supply) at baseline. Number of standard errors are reported. 
FIGURE 4 Downstream Mean Length of Therapy (in Days) for IR Hydrocodone During Follow-up Period by Baseline Pills Per Month and Days Supply Among Nonusers of ER/LA Opioids

\section{A. Baseline Pills Per Month Among Nonusers of ER/LA Opioids}

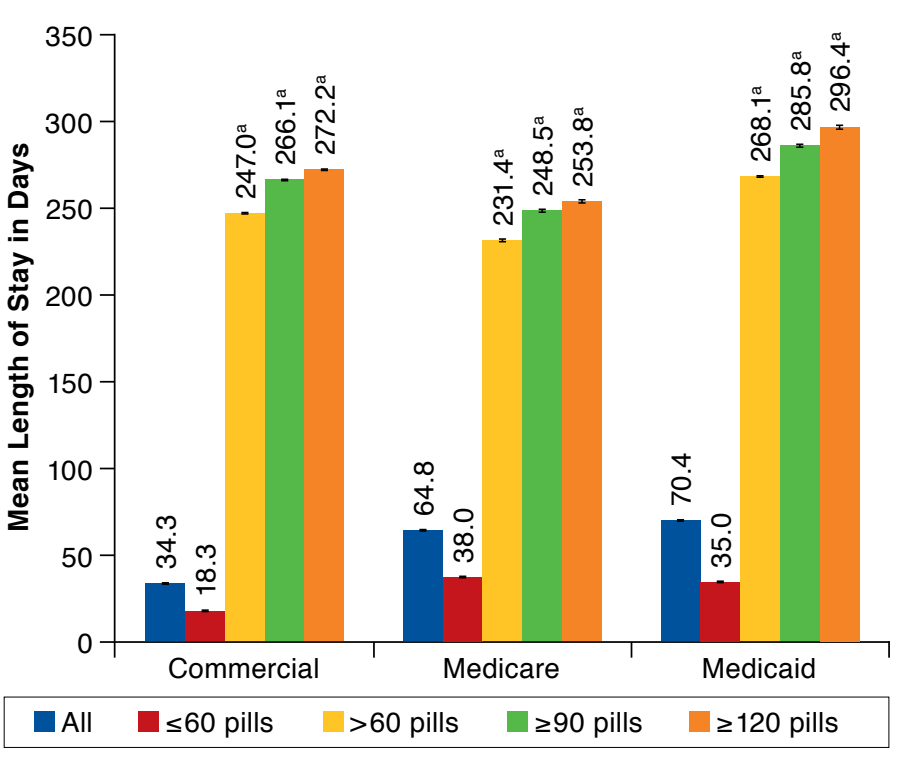

aANOVA analyses found significant difference in the mean length of IR hydrocodone therapy in the follow-up period between reference group ( $<60$ days supply and $\leq 60$ pills per month) and other comparison groups ( $\geq 60$ or $\geq 90$ days supply and $>60, \geq 90$ or $\geq 120$ pills per month, respectively) at baseline.

ER/LA = extended-release/long-acting.

Among nonusers of ER/LA opioids, downstream mean length of therapy with IR hydrocodone during the 1 year of follow-up was 34.3 days, 64.8 days, and 70.4 days for the commercial, Medicare, and Medicaid groups, respectively (Figure 4A). There was a substantial difference in downstream length of IR hydrocodone therapy in the follow-up period when examined by baseline levels of pill count or days supply (Figure 4A-B). Nearly $90 \%$ of nonusers of ER/LA opioids averaged $\leq 60$ pills per month of IR hydrocodone in the baseline period, and they had a downstream average length of IR hydrocodone therapy of 18.3, 38.0, and 35.0 days, respectively, for commercial, Medicare, and Medicaid in the follow-up period, whereas downstream average length of IR hydrocodone therapy was 247.0, 231.4, and 268.1 days, respectively, for nonusers of ER/LA opioids who had $>60$ pills per month in the baseline period. Similarly, nonusers of ER/LA opioids who had $<60$ days supply of IR hydrocodone in the baseline period had a downstream average length of IR hydrocodone therapy of 12.5 , 25.9 , and 23.7 days in the follow-up period, as compared with $240.1,224.4$, and 242.3 days, respectively, for commercial, Medicare, and Medicaid nonusers of ER/LA opioids with $\geq 60$ days supply in the baseline period (Figure 4A-B).
B. Baseline Days Supply Among Nonusers of ER/LA Opioids

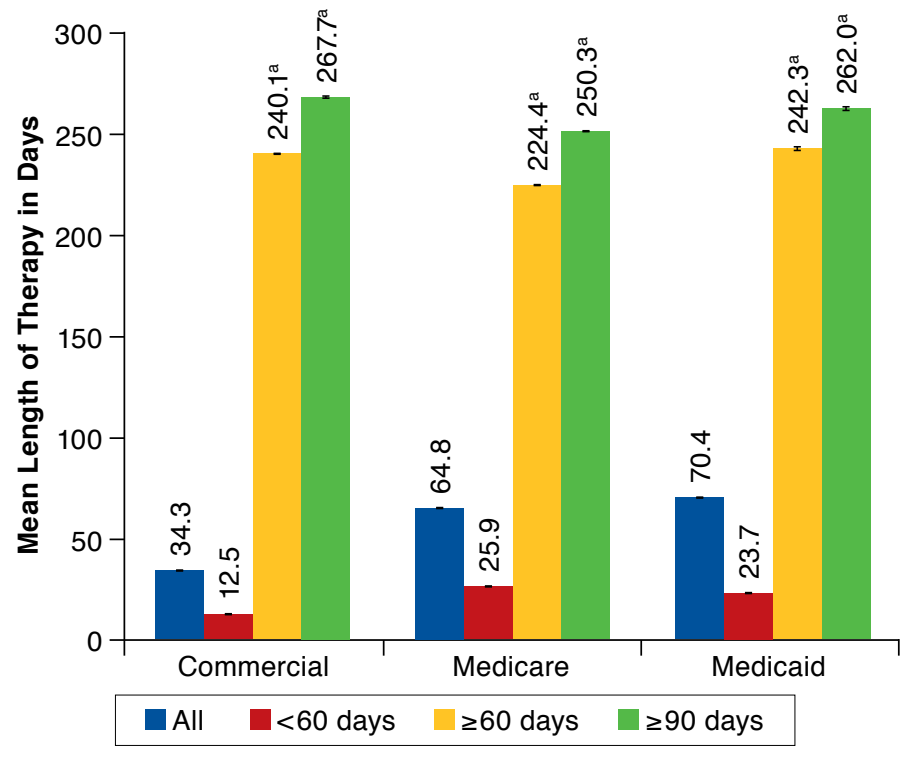

aANOVA analyses found significant difference in the mean length of IR hydrocodone therapy in the follow-up period between reference group $(<60$ days supply and $\leq 60$ pills per month) and other comparison groups ( $\geq 60$ or $\geq 90$ days supply and $>60, \geq 90$ or $\geq 120$ pills per month, respectively) at baseline.

ER/LA = extended-release/long-acting.

\section{Discussion}

Limited research exists on duration of use and prescribing patterns for patients prescribed IR hydrocodone, including the use of ER/LA opioids. This descriptive study sheds light on realworld use patterns of opioid therapy, including the initiation of ER/LA opioids among patients prescribed IR hydrocodone in different payer settings. Opioid prescribing is driven by various factors including, but not limited to, indication for opioid use, comorbidities, severity of pain, socio-demographic characteristics, health status, history of substance abuse, guideline recommendations, and evidence of clinical efficacy.12,13 This study found that most patients ( $90 \%$ ) were prescribed IR hydrocodone for less than 2 months on average in the following year, while the small subset of patients with increased days supply or pills per month of IR hydrocodone in the baseline period continued to be high utilizers in the following year, averaging nearly 8 months of prescribed opioid use.

Paulozzi et al. also examined trends in frequency and duration of overall opioid usage during the 2008-2010 time period, and found similar results to our study. ${ }^{7}$ Among the full study population who used opioids during an initial 6-month period (January-June 2008), only 18\% continued use for the full 3 years of the study (ending July-December 2010). Longer 
durations of use over the course of the study associated with more days of use in the initial 6-month period.

In a separate study, Von Korff et al. (2008) tracked opioid use at 2 managed care health plans in the United States between 1997 and 2006 and classified episodes of opioid use as acute, episodic, long term and high dose, or long term and low dose. ${ }^{6}$ The authors found that acute episodes (use for $<90$ days) accounted for roughly $80 \%$ of all episodes, but that long-term and high-dose (use for $\geq 90$ days with $\geq 120$ days supply, $\geq 10$ prescriptions filled, and average daily dose $\geq 20 \mathrm{mg}$ morphine equivalent) episodes accounted for more than half of the total opioid dosage dispensed over the study time frame. This is consistent with our findings in the IR hydrocodone population: a majority of patients had limited opioid use, but a small fraction of patients continue on for significantly longer-term use.

Existing guidelines have recommended the use of ER/LA opioids over IR opioids for chronic noncancer pain..$^{14,15}$ There is a reported shift to greater prescribing of potent, long-acting opioids in recent years. ${ }^{3,5,9}$ Our study found that a small percentage (1.7\%-2.9\%, depending on payer type) of the overall IR hydrocodone population initiated therapy with an ER/LA opioid in the following year. However, the rate of ER/LA opioid initiation was higher in patients with treatment patterns more consistent with chronic pain management (i.e., patients prescribed $>60$ pills per month or $\geq 60$ days supply in the baseline period) than it was in patients prescribed $\leq 60$ pills per month or $<60$ days supply. Cicero et al. (2009) examined claims data for a privately insured population of chronic pain patients from the Midwest and reported that about 19\% of these patients used ER/LA opioids. ${ }^{16}$ We were not able to identify additional studies that reported the percentage of chronic pain patients using ER/LA opioids.

Other studies have reported a greater use of short-acting hydrocodone than extended-release opioids. A recent analysis conducted by Express Scripts (2014) revealed that half of new opioid users are only taking short-acting opioids; on average, the chronic users of these medications filled 56 shortacting opioid prescriptions over 3 years. ${ }^{1}$ Similarly, Cicero et al. reported that for both acute and chronic pain, the use of immediate-release opioids (53\% for chronic pain, $68.7 \%$ for acute pain) was greater than extended-release opioids (19\% for chronic pain, $0.03 \%$ for acute pain). ${ }^{16}$

This study found that there was slight variation in the rate of initiation by payer type. Higher conversion rate among Medicare patients could be attributed to higher prevalence of chronic pain among the elderly population. ${ }^{17,18}$ Previous studies document greater opioid use in Medicaid beneficiaries. ${ }^{19}$ Medicaid beneficiaries tend to have lower health status and higher prevalence of mental disorders compared to privately insured patients, and that different mix of diagnoses could be associated with higher rates of conversion to ER/LA opioids. ${ }^{20-22}$

The results from this study may help those stakeholders responsible for patient care to better manage and optimize the use of ER/LA opioids within their health plans or care settings. The identification of high users of IR hydrocodone may facilitate an earlier conversion to an ER/LA opioid. This study suggests that $>60$ pills per month or $\geq 60$ days supply of IR hydrocodone could serve as triggers for appropriate transitioning to ER/LA opioid. Further, this study validates targeting the patients receiving $>60$ pills per month and $\geq 60$ days supply of IR hydrocodone, since these patients have significantly longer downstream ER/LA therapy as compared with patients receiving $\leq 60$ pills per month or $<60$ days supply.

\section{Limitations}

This study has several limitations. Pharmacy claims data were used, which represent filled prescriptions reimbursed by insurance rather than actual medication consumption. The data used in this study included only Medicare-eligible patients enrolled in employer-sponsored Medicare Supplemental plans, since there was no access to actual Medicare claims data. It is assumed that these Medicare-eligible patients were representative of patients for whom Medicare is primary payer. Since this was a database study, any error in the data could have affected the results. Potential factors that could influence the prescribing pattern of opioid therapy, such as indications for opioid use, comorbid conditions, history of substance abuse, and health status, were not considered in this study. Direct comparison of the findings reported in this study with the results of other studies should be made with caution and with consideration of the following factors: (a) the study population is composed of IR hydrocodone users only, and (b) patterns of opioid use reported in the literature varies by study sample, data source, types of opioids studied, and the definitions of use (long term vs. short term, long acting vs. short acting). The opioid use described in this study does not include nonmedical use of opioids.

\section{Conclusions}

This study described downstream patterns and duration of opioid use (either IR or ER/LA) among patients prescribed IR hydrocodone. Although IR hydrocodone is the most widely prescribed opioid in the United States, 90\% of patients do not continue with IR hydrocodone for more than 2 months in the following year, while the remaining $10 \%$ of patients with increased days supply or pills per month for IR hydrocodone in the baseline period continue to be high utilizers, averaging nearly 8 months of prescribed opioid use in the following year. A limited proportion of patients prescribed IR hydrocodone converted to ER/LA opioids. Understanding utilization patterns can assist policymakers and physicians, providing an opportunity to identify small subsets of patients to improve ER/LA opioid prescribing. 


\section{Authors}

RAMI BEN-JOSEPH, PhD, and JILL A. BELL, PhD, Purdue Pharma L.P., Stamford, Connecticut. DIANA BRIXNER, PhD, Pharmacotherapy Outcomes Research Center, Department of Pharmacotherapy, University of Utah College of Pharmacy, Salt Lake City; PAMELA HOLLY, JD, Medical Affairs Strategic Research, Purdue Pharma L.P., Stamford, Connecticut; and DOUGLAS S. BURGOYNE, PharmD, Veridicus Health, Salt Lake City, Utah. ANURAAG KANSAL, PhD; CLARK PARAMORE, MSPH; and ABHISHEK CHITNIS, MPharm, PhD, Evidera, Lexington, Massachusetts.

AUTHOR CORRESPONDENCE: Pamela Holly, JD, Purdue Pharma, 201 Tresser Blvd., Stamford, CT 06901. Tel.: 203.588.7318; Fax: 203.588.6659; E-mail: pamela.holly@pharma.com.

\section{DISCLOSURES}

Funding and support for this study was provided by Purdue Pharma L.P. Consulting fees were paid to Evidera by Purdue Pharma L.P. for this study. Kansal, Chitnis, and Paramore are employees of Evidera and were paid consultants to Purdue Pharma for this research. Holly is an employee for Purdue Pharma, and Bell and Ben-Joseph were full-time employees of Purdue Pharma during the design, planning, and execution of the studies and during the preparation of this manuscript. Burgoyne and Brixner were consultants on this project.

Study design was created by Ben-Joseph, Brixner, Paramore, and Burgoyne. Data were collected by Kansal, Chitnis, Bell, Ben-Joseph, and Holly and interpreted by Ben-Joseph, Bell, Kansal, and Holly, with assistance from Brixner, Paramore, Burgoyne, and Chitnis. The manuscript was written by BenJoseph, Bell, Paramore, Chitnis, and Holly, with assistance from Kansal, and revised by Bell and Holly, along with Ben-Joseph, Brixner, Kansal, Paramore, Burgoyne, and Chitnis.

\section{ACKNOWLEDGMENTS}

The authors acknowledge Luke Boulanger and Shuo Yang of Evidera for their assistance in study analysis and manuscript preparation.

\section{REFERENCES}

1. Express Scripts Lab. A nation in pain: focusing on U.S. opioid trends for treatment of short-term and longer term pain. An Express Scripts Report. December 2014. Available at: http://lab.express-scripts.com/publications/ / media/d48ef3ee579848e7bf3f14af536d7548.ashx. Accessed December 29, 2015.

2. Governale L. Outpatient prescription opioid utilization in the U.S., years 2000-2009. U.S. Food and Drug Administration. July 22, 2010. Available at: www.fda.gov/downloads/AdvisoryCommittees/CommitteesMeetingMaterials/ Drugs/AnestheticAndLifeSupportDrugsAdvisoryCommittee/UCM220950. pdf. Accessed December 29, 2015

3. Franklin GM, Mai J, Wickizer T, Turner JA, Fulton-Kehoe D, Grant L. Opioid dosing trends and mortality in Washington State workers' compensation, 1996-2002. Am J Ind Med. 2005;48(2):91-99.
4. Kenan K, Mack K, Paulozzi L. Trends in prescriptions for oxycodone and other commonly used opioids in the United States, 2000-2010. Open Med. 2012;6(2):e41-47.

5. Sullivan MD, Edlund MJ, Fan MY, Devries A, Brennan Braden J, Martin BC. Trends in use of opioids for non-cancer pain conditions 2000-2005 in commercial and Medicaid insurance plans: the TROUP study. Pain 2008;138(2):440-49.

6. Von Korff M, Saunders K, Thomas Ray G, et al. De facto long-term opioid therapy for noncancer pain. Clin J Pain. 2008;24(6):521-27.

7. Paulozzi LJ, Zhang K, Jones CM, Mack KA. Risk of adverse health outcomes with increasing duration and regularity of opioid therapy. J Am Board Fam Med. 2014;27(3):329-38.

8. DeNoon DJ. The 10 most prescribed drugs. WebMD Health News. April 20, 2011. Available at: http://www.webmd.com/news/20110420/the-10-mostprescribed-drugs. Accessed December 29, 2015.

9. Gudin JA. Assessment of extended-release opioid analgesics for the treatment of chronic pain. J Pain Palliat Care Pharmacother. 2013;27(1):49-61.

10. Hansen LG, Chang S. Health research data for the real world: the MarketScan databases. Truven Health Analytics White Paper. July 2011. Available at: http://truvenhealth.com/portals/0/assets/PH_11238_0612_ TEMP_MarketScan_WP_FINAL.pdf. Accessed February 2, 2016.

11. Charlson ME, Pompei P, Ales KL, MacKenzie CR. A new method of classifying prognostic comorbidity in longitudinal studies: development and validation. J Chronic Dis. 1987;40(5):373-83.

12. Argoff CE, Silvershein DI. A comparison of long- and short-acting opioids for the treatment of chronic noncancer pain: tailoring therapy to meet patient needs. Mayo Clin Proc. 2009;84(7):602-12.

13. Sehgal N, Manchikanti L, Smith HS. Prescription opioid abuse in chronic pain: a review of opioid abuse predictors and strategies to curb opioid abuse. Pain Physician. 2012;15(3 Suppl):ES67-92.

14. Kalso E, Allan L, Dellemijn PL, et al. Recommendations for using opioids in chronic non-cancer pain. Eur J Pain. 2003;7(5):381-86.

15. Pedersen L, Borchgrevink PC, Riphagen II, Fredheim OM. Long- or short-acting opioids for chronic non-malignant pain? A qualitative systematic review. Acta Anaesthesiol Scand. 2014;58(4):390-401.

16. Cicero TJ, Wong G, Tian Y, Lynskey M, Todorov A, Isenberg K. Co-morbidity and utilization of medical services by pain patients receiving opioid medications: data from an insurance claims database. Pain. 2009;144(1-2):20-27.

17. Patel KV, Guralnik JM, Dansie EJ, Turk DC. Prevalence and impact of pain among older adults in the United States: findings from the 2011 National Health and Aging Trends Study. Pain. 2013;154(12):2649-57.

18. Reid MC, Eccleston C, Pillemer K. Management of chronic pain in older adults. BMJ. 2015;350:h532.

19. Zerzan JT, Morden NE, Soumerai S, et al. Trends and geographic variation of opiate medication use in state Medicaid fee-for-service programs, 1996 to 2002. Med Care. 2006;44(11):1005-10.

20. Adelmann PK. Mental and substance use disorders among Medicaid recipients: prevalence estimates from two national surveys. Adm Policy Ment Health. 2003;31(2):111-29.

21. Coughlin TA, Long SK, Shen YC. Assessing access to care under Medicaid: evidence for the nation and thirteen states. Health Aff (Millwood). 2005;24(4):1073-83.

22. Ghate SR, Haroutiunian S, Winslow R, McAdam-Marx C. Cost and comorbidities associated with opioid abuse in managed care and Medicaid patients in the United States: a comparison of two recently published studies. J Pain Palliat Care Pharmacother. 2010;24(3):251-58. 
APPENDIX List of Branded and Generic Extended-Release/Long-Acting (ER/LA) Opioids

\begin{tabular}{|c|c|c|}
\hline Trade Name & Generic Name & Sponsor \\
\hline \multicolumn{3}{|l|}{ Branded ER/LA Opioids } \\
\hline Avinza & Morphine sulfate extended-release capsules & Pfizer \\
\hline Butrans & Buprenorphine transdermal system & Purdue Pharma \\
\hline Dolophine & Methadone hydrochloride tablets & Roxane \\
\hline Duragesic & Fentanyl transdermal system & Janssen Pharmaceuticals \\
\hline Embeda $^{a}$ & Morphine sulfate and naltrexone extended-release capsules & Pfizer \\
\hline Exalgo & Hydromorphone hydrochloride extended-release tablets & Mallinckrodt \\
\hline Kadian & Morphine sulfate extended-release capsules & Actavis \\
\hline MS Contin & Morphine sulfate controlled-release tablets & Purdue Pharma \\
\hline Nucynta ER & Tapentadol extended-release oral tablets & Janssen Pharmaceuticals \\
\hline Opana ER & Oxymorphone hydrochloride extended-release tablets & Endo Pharmaceuticals \\
\hline OxyContin & Oxycodone hydrochloride controlled-release tablets & Purdue Pharma \\
\hline \multicolumn{3}{|l|}{ Generic ER/LA Opioids } \\
\hline Fentanyl & Fentanyl extended-release transdermal system & $\begin{array}{l}\text { Actavis, Lavipharm Labs, Mallinckrodt, Mylan Technologies, } \\
\text { Noven, Aveva, Watson }\end{array}$ \\
\hline Methadone hydrochloride & $\begin{array}{l}\text { Methadone hydrochloride tablets; Methadone hydrochloride } \\
\text { oral solution }\end{array}$ & $\begin{array}{l}\text { Roxane, The Pharmanetwork, Mallinckrodt, Sandoz, } \\
\text { Vistapharm }\end{array}$ \\
\hline Morphine sulfate & Morphine sulfate extended-release tablets & $\begin{array}{l}\text { Endo, Mallinckrodt, Mylan, Nesher, Ranbaxy, Rhodes, } \\
\text { Watson Labs }\end{array}$ \\
\hline Oxymorphone hydrochloride & Oxymorphone hydrochloride extended-release tablets & Impax, Actavis \\
\hline
\end{tabular}

